\title{
As Escolas Médicas e os desafios da formação médica diante da epidemia brasileira da Covid-19: das (in)certezas acadêmicas ao compromisso social
}

Sandro Schreiber de Oliveira, Eduardo Arquimino Postal, Denise Herdy Afonso

\section{RESUMO}

Este artigo discute o impacto da pandemia da COVID-19 na formação dos futuros médicos, com ênfase no desafio de adequação do processo formativo ao projeto pedagógico original dos cursos e as Diretrizes Curriculares Nacionais.

Palavras-chave: COVID-19; Pandemia; Atenção Primária à Saúde; Formação Médica; Educação em Saúde.

\section{ABSTRACT}

This article discusses the impact of the COVID-19 pandemic on the formation of future Physicians, with emphasis on the challenge of adequacy of the process training to the original pedagogical project of the courses and the National Curriculum Guidelines.

Keywords: COVID-19; Pandemic; Primary Health Care; Medical Training; Health Education.
Revista da Rede APS 2020

Publicada em: 15/04/2020

DOI:10.14295/aps.v2i1.69

Sandro Schreiber de Oliveira

(Universidade Federal do Rio Grande, Universidade Católica de Pelotas, Associação Brasileira de Educação Médica/Abem, Brasil);

Eduardo Arquimino Postal (Universidade Católica de Pelotas, Associação Brasileira de Educação Médica/Abem, Brasil);

Denise Herdy Afonso (Universidade do Estado do Rio de Janeiro, Associação Brasileira de Educação Médica/Abem, Brasil)

Correspondência para:

Sandro Schreiber de Oliveira sandro.schreiber@yahoo.com.br 
A epidemia de Covid-19 no Brasil já se constitui uma das mais impactantes questões de saúde pública na realidade do País e no mundo moderno, em decorrência das múltiplas consequências e tensões que atingem a nossa sociedade. Ainda que o foco esteja na proteção aos usuários e à comunidade, o cenário de epidemia no Brasil interferiu de forma abrupta no processo educacional da formação médica e de outros cursos da saúde, exigindo um remodelamento emergencial e demandando atenção e diálogo ágil entre educadores, gestores e sociedade.

A preocupação com o impacto da epidemia na formação dos futuros médicos, está presente ao redor do mundo $^{1}$, com ênfase no desafio de adequação do processo formativo ao cenário de epidemia, em função da não integralização das cargas horárias preconizadas, do deslocamento das atividades previstas para alguns campos de prática diversos, da possibilidade e antecipação das formaturas e do uso adicional de tecnologias educacionais à distância, que podem impactar a execução do projeto pedagógico original dos cursos, bem como das próprias diretrizes curriculares nacionais.

No Brasil, na busca de respostas aos distintos cenários da epidemia e atentos as experiências internacionais, o Governo Federal, em especial o Ministério da Saúde, tem publicado diversas normativas legais que definem ações estratégicas para o enfrentamento da epidemia. $\mathrm{Na}$ interface saúde-educação, muitas determinações exigem reorganização do processo de trabalho na atenção à saúde e consequentemente na integração ensinoserviço. Em geral, as normativas emanadas do Ministério da Educação buscam um alinhamento das práticas educacionais ao momento sanitário do país.

$\mathrm{Na}$ perspectiva de organização das ações de saúde, a epidemia amplifica desafios logísticos relacionados a segurança do paciente $e$ profissionais de saúde, a (re)definição de fluxos institucionais, à adequada comunicação de protocolos de cuidado e, em especial, a integração de ações nos distintos níveis de atenção e destes com as escolas médicas. 0 desafio no âmbito educacional se inicia no reconhecimento do estudante de medicina como um potencial vetor de contaminação. A resposta inicial do conjunto de escolas médicas brasileiras, se assemelha a de outros países ${ }^{1,2,3}$, com suspensão imediata dos estágios curriculares, atendendo as normativas sanitárias de distanciamento social, com o objetivo realizar diagnóstico situacional da sua rede de atenção à saúde. E a partir disso, replanejar as práticas educacionais, considerando a redução da exposição dos acadêmicos aos cenários de risco e colaborando com as estratégias de mitigação e contenção da propagação do Coronavirus.

Dados levantados pela Associação Brasileira de Educação Médica - Abem ${ }^{4}$, alcançando informações de $82 \%$ das escolas médicas do país, revelam que aproximadamente $90 \%$ das escolas médicas suspenderam suas atividades acadêmicas, práticas e teóricas, no período entre 16 e 31 de março de 2020. A suspensão parcial das atividades acadêmicas do 1 을 ao 4 으 período, considerando, excepcionalmente, a possibilidade de cumprimento de $20 \%$ da carga horária curricular em atividades a distância, revela o desafio no campo pessoal dos alunos. Desorganização, desestímulo, insegurança, angústia e aflição são palavras que são ouvidas com maior frequência nos ambientes de ensino. A isso soma-se os desafios do aprendizado virtual, que tem sido implementado abruptamente na tentativa de algumas escolas para preservar atividades parciais. Por vezes, não se nota a sensibilidade e a empatia das escolas com os alunos, que estão sob uma carga adicional de estresse, fruto dos seus dilemas pessoais e os compromissos da formação.

A consequência imediata desta estratégia de interrupção, foi o esvaziamento dos serviços de saúde onde havia inserção de acadêmicos. Entretanto, somente em $18 \%$ dos casos essa decisão foi compartilhada com a rede de saúde parceira das escolas, como aponta o panorama realizado pela ABEM. Decisões desse cunho, necessariamente, deveriam ser pactuadas no processo de integração ensino-serviço considerando as demandas de todos os agentes 
envolvidos e os impactos na assistência à comunidade nesse momento de calamidade.

Assim como em outros países essa medida deve ser temporária, levando apenas o tempo necessário para o planejamento interno da instituição de ensino, a organização de fluxos e logística das unidades de saúde, a capacitação de profissionais de saúde e o alinhamento de políticas públicas que mantenham o transporte local adequado para a circulação dos estudantes. Na orientação das escolhas de escolas e serviços é fundamental considerar a responsabilidade pedagógica e social das escolas médicas orientadas pelas Diretrizes Curriculares Nacionais (DCNs) de $2014^{5}$ em formar um egresso com perfil para exercer seu papel social de forma crítica e reflexiva.

A autorização para ampliação do uso de EaD nas graduações da área da saúde ${ }^{67}$ impõe importantes desafios. A ABEM identificou que, das escolas médicas que definiram pela paralisação inicial de atividades presenciais, $80 \%$ buscaram nos recursos da educação a distância alternativa para manutenção do vínculo acadêmico, orientação e continuidade dos componentes curriculares. Ainda que tenha havido a intenção desta oferta, nem todas as instituições conseguiram efetivar esta mudança num curto espaço de tempo, considerando os desafios das plataformas virtuais, as habilidades docentes e a adesão de alunos.

Neste momento, em caráter de excepcionalidade, os recursos de EaD podem atender à orientação de distanciamento social preservando a vinculação e suporte aos acadêmicos. No entanto, o acesso a internet para vídeo aulas ou trânsito de arquivos pesados ainda não é uma realidade em todos os municípios de origem dos estudantes ou mesmo pelo poder aquisitivo limitado de alguns. Ainda que a tecnologia digital traga para o cenário da formação dos profissionais de saúde um ganho importante na capacitação para uma ampliação do cuidado em saúde digital, não identificamos a perspectiva substitutiva destas estratégias às atividades presenciais do curso médico. Importante destacar que em cenários de caos e carência de certezas é campo fértil para o surgimento de movimentos originados do mercado que podem perverter a lógica da educação. Nesse sentido, devemos estar atentos aos movimentos e aos discursos que podem surgir indicando um caminho para a substituição das atividades educacionais presenciais para aquelas em EAD. Esse movimento já é bem sinalizado no cenário internacional, sendo apontada como uma alternativa para a escola médica no futuro. Há de se ter em mente a quem serve esta lógica, e ao prejuízo que seu uso desregulamentado e predominante no escopo das alternativas metodologias, pode vir a causar no processo de aprendizado. Por isso, torna-se-á iminente e indispensável um amplo debate sobre o espaço da EaD no cenário pós-pandemia, considerando todos os aspectos envolvidos na formação.

No entanto, o desafio mais dramático está em equacionar os impactos da epidemia sobre os estágios curriculares, nos últimos dois anos da graduação médica, correspondendo a, no mínimo, 35\% da carga horária dos cursos. Estes estão afetados por quatro principais situações: a suspensão integral das atividades práticas por parte de muitas escolas, o chamado do Ministério da Saúde para o trabalho voluntário destes estudantes, a orientação às escolas para que considerem o cumprimento desta carga horária como equivalente de seus estágios curriculares e a potencial antecipação de formaturas. Podemos afirmar que estes desafios não são exclusivos do Brasil a partir da realidade imposta pela epidemia: Estados Unidos, Itália, Reino Unido e outros países já implementaram alternativas semelhante ${ }^{8}$.

De forma articulada, o Ministério da Educação e - Ministério da Saúde, legislam para criar as condições excepcionais de participação voluntária dos alunos de algumas áreas de saúde ${ }^{9}$. A partir destas legislações, ainda que as escolas médicas permaneçam com suas atividades acadêmicas suspensas, muitos alunos serão cativados pela oportunidade de atuar como voluntários, em especial pela oportunidade de bonificação para acesso aos programas de residência, retornando aos serviços de saúde quando e se convocados. É 
possível que este retorno dos acadêmicos ao serviço ocorra em situação de sobrecarga do sistema de saúde, dos profissionais das unidades de saúde e com tensionamento em relação ao quantitativo de insumos disponíveis.

Ainda que as respectivas Portarias não definam atribuições específicas e obrigatórias das escolas médicas de vinculação dos alunos voluntários, compreendemos como oportuna a atuação das instituições de ensino promovendo o acompanhamento dos impactos destas atividades no aprendizado profissional e pessoal dos alunos. A ABEM, em nota recente ${ }^{10}$, elenca recomendações aos gestores de saúde e, em especial às escolas médicas, para que preservem seu compromisso social com a rede de assistência à saúde e a comunidade acadêmica.

A autorização para a antecipação da formatura de estudantes da área da saúde ${ }^{11}$ deverá provocar a adesão de algum percentual de alunos, considerando que muitos estágios de Internato permanecem com atividades suspensas além de seu desejo em atuar como médico em situação excepcional. Estes egressos talvez estejam coerentes com o perfil definido pelas DCNs vigentes, com ampla experiência nos cenários da APS, urgência e emergência e saúde mental e aptos a atuar imediatamente na rede de saúde organizada para atendimento a epidemia da COVID19 e as necessidades de saúde. No entanto, muitas escolas permanecem com desafios para adequação às DCNs e com modelos curriculares fragmentados e hiperespecializados.

No cenário atual de excepcionalidades e incertezas, não podemos nos furtar em debater os possíveis impactos da epidemia de COVID19, a médio prazo, para nossa sociedade. Passada a epidemia, como será a mais jovem força de trabalho médico no Brasil? O cotidiano da maioria dos egressos recém-formados, até 2020, era de atuação imediata na atenção primária e cenários de urgência e emergência, sem cursar programas de residência médica. No contexto da suspensão de atividades acadêmicas, redirecionamento de cenários de atuação e antecipação de formatura, não há garantia que o médico formado nessas condições tenha vivenciado a prática nesses cenários. Uma vez que, existindo a possibilidade de antecipar a formatura, a partir do cumprimento de $75 \%$ da carga horária dos estágios, considerando uma carga-horária mínima 30\% em APS e urgência e emergência, e que a maioria das escolas organiza seus estágios em rodízios por área, uma após outra, é possível que uma fração grande desses egressos possa receber seus diplomas de médico tendo cumprido apenas $15 \%$ da carga horária destas duas áreas somadas, ou mesmo nenhuma carga horária de alguma delas.

A demanda atual do sistema de saúde nacional por profissionais com formação generalista, humanitária e reflexiva poderá revelar se as escolas estarão prontas para liberar profissionais egressos com este perfil. Essa talvez seja uma grande questão deste momento: depois de quase 10 anos das DCNs, avançamos de maneira satisfatória na formação das futuras gerações médicas aptas a atender às necessidades de saúde da população? O cenário pós crise poderá trazer respostas e oportunidades para retomar esse debate.

Importante considerar que "nada será como antes, amanhã". A flexibilidade necessária para a adaptação do setor da saúde e da educação e consequentemente das práticas e de seus profissionais durante o período da epidemia poderá deixar como aprendizado a capacidade de encontrar nas decisões compartilhadas, no trabalho colaborativo e na definição de prioridades, o caminho para superar os desafios da formação médica pós epidemia. Quem sabe será necessário planejar um acompanhamento longitudinal dos egressos do período da epidemia na perspectiva da educação permanente ou até mesmo retornar ao debate da residência médica universal. 


\title{
NOTAS E REFERÊNCIAS
}

\author{
${ }^{1}$ Ahmed, Hanad; Allaf, Mohammed; Elghazaly, Hussein. COVID-19 and medical education. THE LANCET. \\ MARÇO 2020.
}

${ }^{2}$ Rose S. Medical Student Education in the Time of COVID-19. JAMA. Published online March 31, 2020. doi:10.1001/jama.2020.5227

${ }^{3}$ Ferrel M N, Ryan J J (March 31, 2020) The Impact of COVID-19 on Medical Education. Cureus 12(3): e7492. doi:10.7759/cureus.7492

${ }^{4}$ Abem. Associação Brasileira de Educação Médica. Resultados preliminares do diagnóstico das escolas médicas na epidemiacovid-19. Disponível em: < https://website.abem-educmed.org.br/resultadospreliminares-diagnostico-escolas-medicas/> Acesso em: 2020, abril 2020.

${ }^{5}$ Brasil. Ministério da Educação. Conselho Nacional de Educação, Câmara de Educação Superior. Diretrizes Curriculares Nacionais do Curso de Graduação em Medicina. Diário Oficial da União, Brasília, 23 de junho de 2014. Seção 1, p.8-11. Brasília, 2014

${ }^{6}$ BRASIL. PORTARIA No 342. Dispõe sobre a substituição das aulas presenciais por aulas em meios digitais enquanto durar a situação de pandemia do Novo Coronavírus. Diário Oficial da União: 18/03/2020. Edição: 53. Seção: 1. p. 39. Brasília, DF, 18 de março 2020.

7 BRASIL. PORTARIA No 345. Altera a Portaria MEC no 343, de 17 de março de 2020 . Diário Oficial da União: 18/03/2020. Edição: 54-D. Seção: 1 - Extra. p. 1. Brasília, DF, 19 de março 2020.

${ }^{8}$ Harvey Anna. Covid-19: medical schools given powers to graduate final year students early to help NHS BMJ 2020; 368 :m1227

9 BRASIL. PORTARIA No 356. Dispõe sobre a regulamentação e operacionalização do disposto na Lei no 13.979, que estabelece as medidas para enfrentamento da emergência de saúde pública de importância internacional decorrente do coronavírus. Diário Oficial da União: 18/03/2020. Edição: 49. Seção: 1. p.: 185. Brasília, DF, 12 de março 2020

${ }^{10}$ Abem. Associação Brasileira de Educação Médica. Recomendação da Abem a gestores e acadêmicos de cursos de Medicina. Disponível em: <https://website.abem-educmed.org.br/wpcontent/uploads/2020/04/Recomendações-da-ABEM_-MP-colação-de-grau.pdf> Acesso em: 2020, abril 2020.

${ }^{11}$ Abem. Associação Brasileira de Educação Médica. Recomendação da Abem a gestores e acadêmicos de cursos de Medicina. Disponível em: <https://website.abem-educmed.org.br/wpcontent/uploads/2020/04/Recomendações-da-ABEM_-MP-colação-de-grau.pdf> Acesso em: 2020, abril 2020. 